\section{Sticky Feet: From Animals to Materials}

\section{Costantino Creton and Stanislav Gorb, Guest Editors}

\begin{abstract}
Many insects and some larger animals, such as geckos, skinks, and tree frogs, can easily climb vertical walls and even walk on the ceiling. These abilities require a method to attach the feet strongly but reversibly to a variety of surfaces-smooth or rough, hydrophilic or hydrophobic, clean or containing contaminants. This issue of MRS Bulletin examines how fibrils, absorbed water layers, geometry, and other factors make reversible adhesion possible, and how this understanding might be applied to robots and other artificially created structures that can climb walls, walk on ceilings, and get to other hard-to-reach places.
\end{abstract}

Yet many animals, including flies, beetles, rather large spiders, and gekkonid lizards, have feet covered with tiny specialized hairs that allow them to run fast on the ceiling and support a force many times their weight. The foot of a chrysomelid beetle is shown as an example in Figure 1. Tree frogs, bees, and grasshoppers can do it without hairs by using the highly specialized material structure of their adhesive feet, which enables them to match perfectly the surface profile of the substrate. ${ }^{17-21}$ The question is: Can we learn from these animals how to develop new materials able to reversibly stick to a variety of surfaces?

\section{"Sticky Feet": Morphology and Mechanisms}

Morphological research on the gecko has shown that adhesion is based on a hierarchical structure of fibrils that become smaller toward the contact regions with the surface. ${ }^{1,6,22,23}$ The surface is contacted by thousands of 200-nm-long and 15-nm-thick stiff keratin structures called spatulae-thin fibers tipped with tapered plates-which form individual attachment points. Such a structure may rely solely on van der Waals forces to stick to the surface because of the multiple attachment points and extreme thinness of the contacting elements. An adsorbed water layer present on the majority of real surfaces under ambient conditions may enhance adhesion in this system by capillarity. ${ }^{24}$

Similar geometrical effects are known from numerous species of insects; however, because of the larger size of their spatulae, insects additionally use fluid
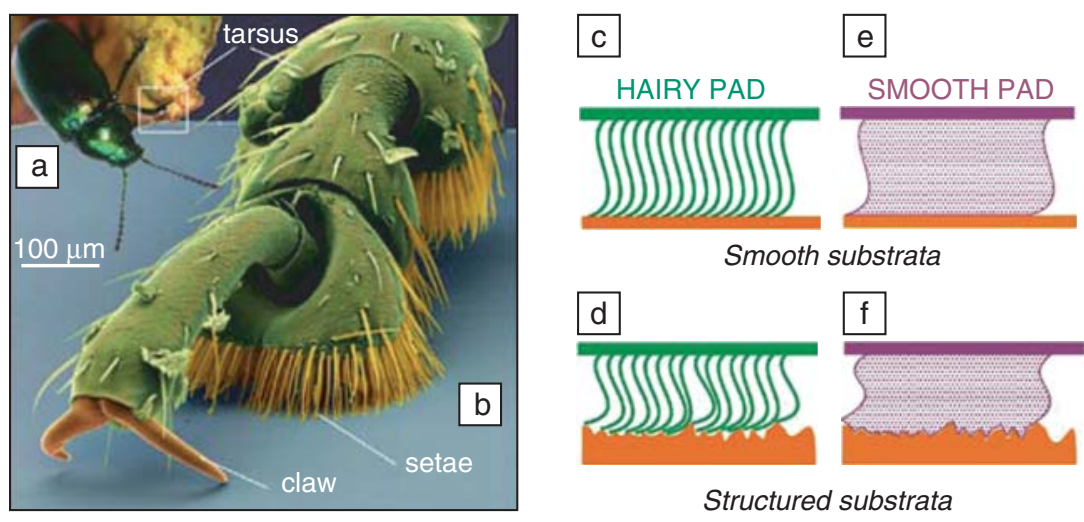

Figure 1. Biological systems with reversible adhesion. (a) Chrysomelid beetle Gastrophysa viridula. (b) Foot (tarsus) of the beetle attached to a smooth surface (from Reference 43). Diagram of the action of (c), (d) hairy and (e), (f) smooth pad attachment systems on smooth and structured substrata (from Reference 44). Both hairy and smooth systems are able to adapt to the smooth and rough surface profiles. 
secretion to enhance capillary adhesion between their spatulae and the substrate. $^{25,26}$

The details of the mechanisms for attachment and detachment of animal feet remain complex and difficult to reproduce artificially. However, several laboratories have designed biologically inspired artificial surfaces (Figure 2) to investigate the more tractable problems ${ }^{8,27-32}$ of the effect on macroscopic adhesive forces and energies of replacing a single large contact with many more much-smaller contacts.

\section{In This Issue}

In this issue of MRS Bulletin, we first present the biological point of view through the work of two specialists in the area of reversible biological adhesion, Kellar Autumn and Jon Barnes. They present tutorials on the current understanding of the main mechanisms by which these attachment pads work in nature.

These two articles are followed by a more theoretical article from Bo Persson, who is a world specialist on friction and adhesion phenomena of rough surfaces. He contributes his view on the fundamental physical principles of locomotion based on contact adhesion. This overview provides a transition from the study of biological systems to the design of bioinspired but necessarily simpler artificially patterned adhesive surfaces.

The next two articles, by Jagota et al. and Chan et al., discuss in more detail the mechanics of fibrillar adhesion. In particular, these authors outline how to optimize

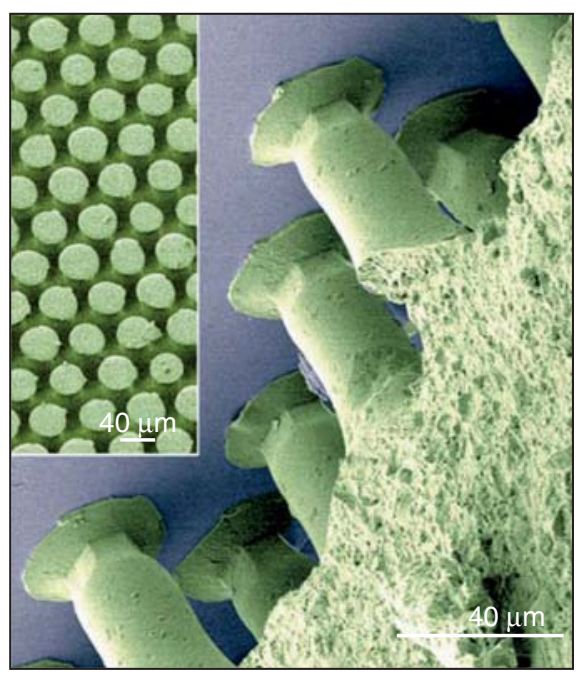

Figure 2. Patterned polymer surface with adhesive strength more than six times greater than flat specimens made of the same polymer (from Reference 33). the ratio of diameter to length of the fibrils in relation to the modulus, and discuss in detail the difference in crack propagation and crack initiation between different surface patterns. A properly designed fibrillar interface will fail by multiple crack initiation rather than by the propagation of a single crack. This important point is at the heart of the design of bio-inspired fibrillar structures.

The article by Anand Jagota, Nicolas Glassmaker, Tian Tang, and Herbert Hui first addresses the question of why simple fibrillar interfaces can be of interest in making adhesive surfaces. The authors then present some of the challenges facing materials scientists in designing functional fibrillar interfaces and the specific solid-mechanics problems that need to be overcome to proceed from the general concept to a practically useful material.

Some of the questions posed in the Jagota article are addressed in the next article contributed by Edwin P. Chan, Alfred J. Crosby, Christian Greiner, and Eduard Arzt, who present the state of the art in the emerging field of optimization of fabricated fibrillar structures for reversible adhesion, both from the theoretical and experimental points of view.

For materials scientists, these studies emphasize the necessity to couple the inherent material properties of the adhering material with the geometry of the contact. $^{33-37}$ The efficiency of natural systems cannot of course be copied directly, but some of the concepts can be translated to the materials world to design surfaces with optimized micro- and nanostructures in terms of wavelength, depth, and stiffness. Some of these functional principles are shown in Figure 3.

Finally, this issue would not be complete without an article emphasizing applications of the biomimetic strategies. The most promising area for these applications is that of robotics, where the design of intelligent robots requires an efficient and reliable locomotion system, possibly inspired by nature. Insects-in particular, cockroaches, beetles, and flies-provide excellent models in terms of locomotion in rough and adverse terrain. Several solutions implemented by insects ${ }^{38-41}$ can be adapted to artificial motion systems. Some examples are discussed in the final article, by Kathryn Daltorio, Andrew Horchler, Terence Wei, Roy Ritzmann, Roger Quinn, Stanislav Gorb, and Andrei Peressadko.

In conclusion, the take-away message for the materials specialist is that there is a close link between mechanics, chemistry, and physics when it comes to adhesion. Nature provides a rich source of solutions for many surface-related problems in materials science (for a review, see Reference 42), but mimicking them is only possible after attaining a detailed understanding of functional principles. The examples from biology emphasize the importance of mechanics, but the artificial solutions are not achievable without a combination of clever mechanical design and well-adapted materials solutions.

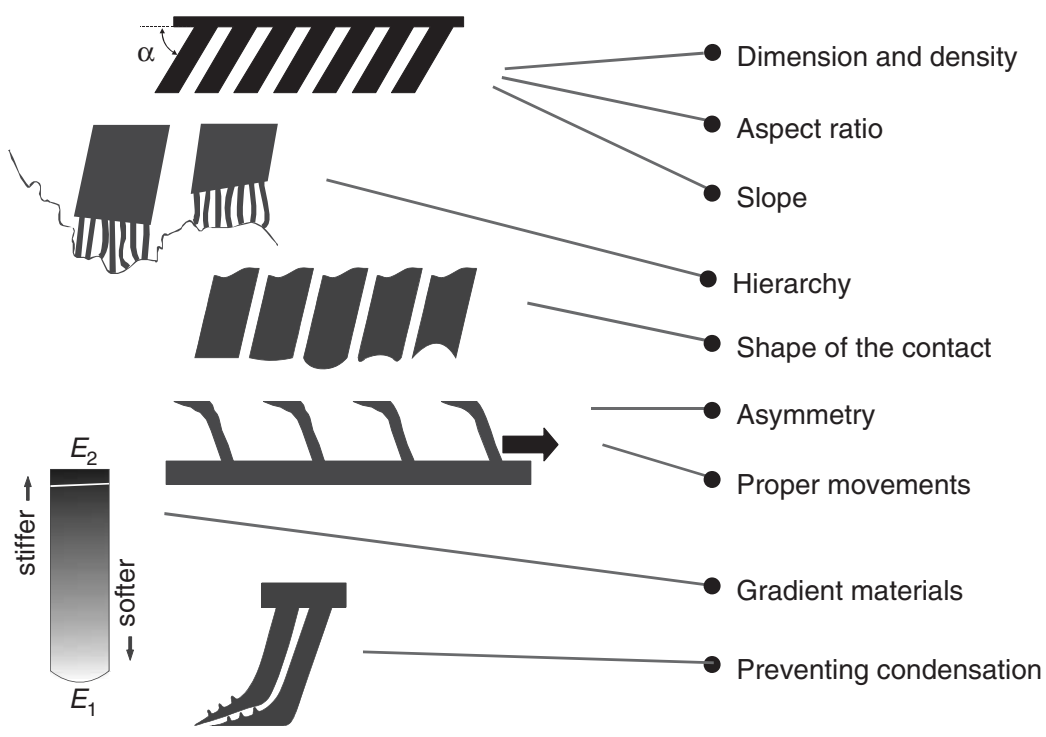

Figure 3. Some functional principles involved in reversible biological adhesive systems. Their simultaneous implementation in one artificial system is hardly possible. However, depending on the requirement for a particular material or system, one principle or a combination of a few of them can be implemented. $E_{1}$ and $E_{2}$ are Young's moduli, and $\alpha$ is a slope angle of fibrils. 


\section{References}

1. K. Autumn et al., Nature 405, 681 (2000).

2. T.A. Ba-Omar, J.R. Downie, W.J.P. Barnes,

J. Zool. London 250, 267 (2000).

3. E. Bauchhenss, Zoomorphologie 93, 99 (1979).

4. W. Federle, E.L. Brainerd, T.A. McMahon, B.

Hölldobler, Proc. Nat. Acad. Sci. USA 98, 6215

(2001).

5. S.N. Gorb, Proc. R. Soc. London B 265, 747

(1998).

6. U. Hiller, Z. Morphol. Tiere 62, 307 (1968)

7. G. Walker, A.B. Yule, and J. Ratcliffe, J. Zool. London 205, 297 (1985)

8. A.K. Geim et al., Nat. Mater. 2, 461 (2003).

9. A. Jagota, S.J. Bennison, Integr. Comp. Biol. 42, 1140 (2002)

10. T. Tang, C-Y. Hui, N.J. Glassmaker, J. R. Soc. Interface 2, 505 (2005).

11. O. Betz, J. Exp. Biol. 205, 1097 (2002).

12. S. Niederegger, S. Gorb, J. Insect Physiol. 49, 611 (2003).

13. G. Hanna, W.J.P. Barnes, J. Exp. Biol. 155, 103 (1990).

14. D.J. Irschick et al., Biol. J. Linn. Soc. 59, 21 (1996).

15. B. Vanhooydonck, A. Andronescu, A. Herrel, D.J. Irschick, Biol. J. Linn. Soc. 85, 385 (2005).

16. C. Creton, MRS Bull. 28 (6), 434 (2003).
17. Y. Jiao, S.N. Gorb, M. Scherge, J. Exp. Biol. 203, 1887 (2000).

18. U.D. Kendall, Z. Zellforsch. 109, 112 (1970).

19. P.P. Perez Goodwyn et al., J. Comp. Physiol. A 192, 1233 (2006).

20. M. Schargott, V.L. Popov, S.N. Gorb, J. Theor. Biol. 243, 48 (2006).

21. E.H. Slifer, Ann. Entomol. Soc. Am. 43, 173 (1950).

22. G. Huber, S.N. Gorb, R. Spolenak, E. Arzt, Biol. Lett. 1, 2 (2005).

23. N.W. Rizzo et al., J. R. Soc. Interface 3, 441 (2006).

24. G. Huber et al., Proc. Nat. Acad. Sci. USA 102, 16293 (2005).

25. E. Arzt, S. Gorb, R. Spolenak, Proc. Nat. Acad. Sci. USA 100, 10603 (2003).

26. M. Scherge, S.N. Gorb, Biological Micro- and Nanotribology: Nature's Solutions (Springer, Berlin, 2001).

27. N.J. Glassmaker, A. Jagota, C.-Y. Hui, J. Kim, J. R. Soc. London Interface 1, 23 (2004).

28. C-Y. Hui, N.J. Glassmaker, T. Tang, A. Jagota, J. R. Soc. London Interface 1, 35 (2004).

29. A. Peressadko, S.N. Gorb, J. Adhes. 80, 247 (2004).

30. M. Sitti, R.S. Fearing, IEEE Int. Conf. Robotics and Automation (2003) pp. 1-7.
31. B. Yurdumakan, N.R. Raravikar, P.M. Ajayan, A. Dhinojwala, Chem. Commun. 30, 3799 (2005)

32. M.T. Northen, K.L. Turner, Nanotechnology 16, 1159 (2005)

33. S. Gorb, M. Varenberg, A. Peressadko, J. Tuma, J. R. Soc. Interface 4, 271 (2007)

34. S. Niederegger, S. Gorb, Y. Jiao, J. Comp. Physiol. A 187, 961 (2002).

35. R. Spolenak, S. Gorb, H. Gao, E. Arzt, Proc R. Soc. London A 461, 305 (2005).

36. R. Spolenak, S. Gorb, E. Arzt, Acta Biomater 1, 5 (2005).

37. M.T. Northen, K.L. Turner, Sens. Actuators, A 130, 583 (2006)

38. H. Cruse, Physiol. Entomol. 4, 212 (1979).

39. L. Frantsevich, H. Cruse, J. Insect Physiol. 51, 1092 (2005)

40. A.L. Ridgel, R.E. Ritzmann, P.L. Schaefer, J. Exp. Biol. 206, 4453 (2003).

41. A.L. Ridgel, R.E. Ritzmann, Ageing Res. Rev. 4, 23 (2005)

42. S.N. Gorb, in Biomimetics: Biologically Inspired Technologies, Y. Bar-Cohen, Ed. (CRC Press, Boca Raton, FL, 2006) pp. 381-397.

43. S.N. Gorb, Am. Entomol. 51, 31 (2005).

44. S.N. Gorb, Attachment Devices of Insect Cuticle (Kluwer Academic Publishers, Dordrecht, 2001).

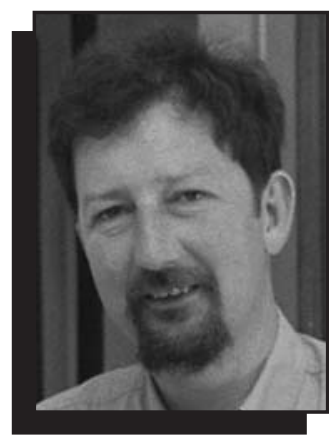

Costantino Creton

Costantino Creton,

Guest Editor for this issue of MRS Bulletin, is CNRS research director in the Laboratoire de Physico-Chimie des Polymères et Milieux Dispersés (PPMD) at the Ecole Supérieure de Physique et Chimie Industrielles (ESPCI) in Paris, France. He earned his $\mathrm{PhD}$ degree in materials science and engineering from Cornell University in 1991. After working as a postdoctoral researcher at IBM

Almaden Research

Center, Creton joined the

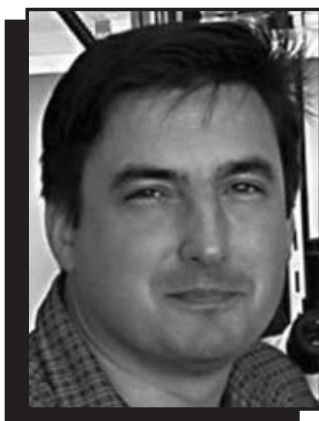

Stanislav Gorb

Laboratoire de PhysicoChimie Structurale et Macromoléculaire of the ESPCI as a postdoctoral associate in 1993. He became a CNRS permanent researcher in 1994 and has worked at PPMD since 2001.

Creton is well known internationally in the area of polymer interfaces and mechanical and adhesive properties of polymeric materials. His current research interests focus on the relationship between the chemical and mesostructures of soft materials and their large strain, fracture, and adhesive properties. Creton also is interested in pressure-sensitive adhesives, hydrogels, elastomers, and soft nanocomposites.

He was honored with the Best Paper Award from the Adhesion Society in 2000 and the Polymer Prize from the French Polymer Group in 2002. Creton has given over 40 invited and plenary lectures at international conferences.

Creton can be reached at Laboratoire PPMDESPCI, 10 rue Vauquelin, 75231 Paris Cédex 05, France; tel. 33-1-40-79-4683, fax 33-1-40-79-46-86, and e-mail costantino. creton@espci.fr.

Stanislav Gorb, Guest Editor for this issue of MRS Bulletin, is a group leader at the Max Planck Institute for Metals Research in Stuttgart, Germany. He received his $\mathrm{PhD}$ degree in zoology and entomology at the Schmalhausen Institute of Zoology of the Ukrainian Academy of Sciences in Kiev. Gorb was a postdoctoral researcher at the University of Vienna, a research assistant at University of Jena, a group leader at the Max Planck Institute for Developmental Biology in Tübingen, and a visiting professor at both the University of Washington and Nanjing University of

Astronautics and

Aeronautics in China.

Gorb's research focuses on morphology, structure, biomechanics, physiology, and evolution of surface-related functional systems in animals and plants, as well as the development of biologically inspired technological surfaces and systems. He received the Schlossmann Award in Biology and Materials Science in 1995 and was the 1998 BioFuture Competition winner for his works on biological attachment devices as possible sources for biomimetics. Gorb has authored three books, including Attachment Devices of Insect Cuticle and Biological Micro- and Nanotribology; more than 100 papers in peerreviewed journals; and three patents.

Gorb can be reached at the Evolutionary Biomaterials Group, Department of Thin Films and Biological Systems, Max Planck Institute for Metals Research, Heisenbergstrasse 3, 70569 Stuttgart, Germany; e-mail s.gorb@mf.mpg.de.

Eduard Arzt is a professor of physical metallurgy/metal physics at the University of Stuttgart and a director at the Max Planck Institute for Metals Research. He received his $\mathrm{PhD}$ degree in physics and mathematics at the University of Vienna. Arzt was a postdoctoral research 


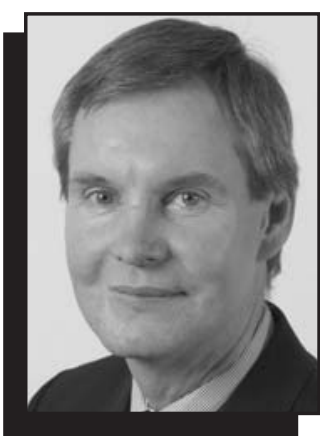

Eduard Arzt

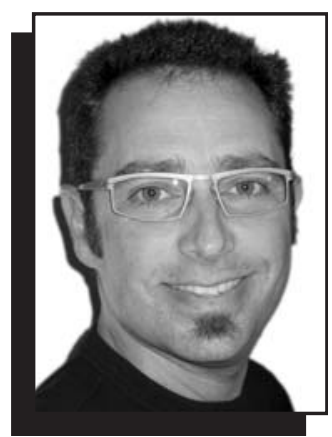

Kellar Autumn

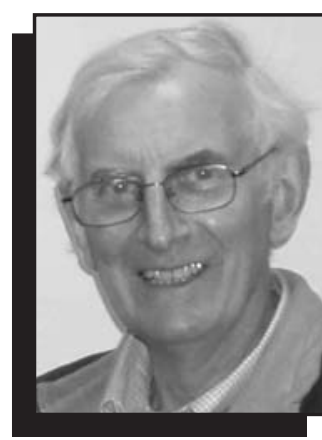

W. Jon. P. Barnes

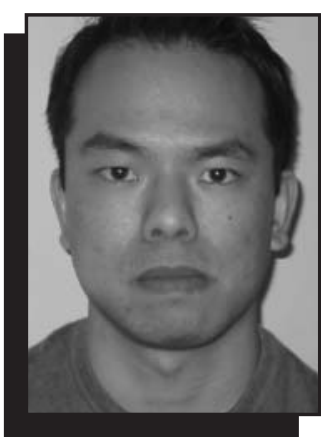

Edwin P. Chan

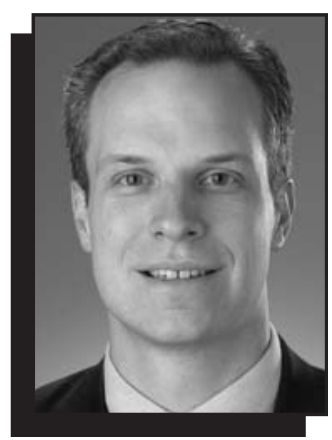

Alfred J. Crosby
USA; tel. 503-768-7502, fax 503-768-7658, e-mail autumn@lclark.edu, and URL www.lclark. edu/ autumn.

W. Jon. P. Barnes is an honorary research fellow at the Centre for Cell Engineering at the University of Glasgow. After obtaining BSc and $\mathrm{PhD}$ degrees in zoology at the University of St. Andrews, he joined the staff of the Zoology Department of Glasgow in 1966, retiring as Reader in 2006. Barnes was a biologist at Glasgow for his entire academic career. His research combines an interest in neuroethology (the ways in which the behaviors of simple animals are controlled by their nervous systems) and biomechanics. In the latter area, his research has been directed at the mechanisms of wet adhesion used by tree frogs. These systems are being studied at all levels between the behavioral and the cellular, including their implications for biomimetics.

Barnes can be reached at the Centre for Cell Engineering, Joseph Black Building, University of Glasgow, Glasgow G12 8QQ, Scotland, UK; tel./ fax 0141-330-3730 and e-mail j.barnes@bio. gla.ac.uk.
Edwin P. Chan is a PhD student in the Polymer Science and Engineering Department at the University of

Massachusetts Amherst under the guidance of Alfred J. Crosby. Chan received his BS degree in materials science and engineering at the Pennsylvania State University and his MS degree in materials science and engineering at MIT under the guidance of Edwin L. Thomas. His research interests center on bio-inspired design of structured materials for control of polymer adhesion, with special emphasis on the development and use of wrinkling instabilities for microfabrication.

Chan received the Alan Gent Distinguished Student Paper Award from the Adhesion Society in 2006.

Chan can be reached at University of

Massachusetts, Polymer Science and Engineering Department, 120 Governors Dr., Amherst, MA 01003, USA; e-mail epc@mail.pse.umass.edu.

Alfred J. Crosby is an assistant professor in the Polymer Science and Engineering Department at the University of Massachusetts Amherst. He received his BS degree in civil engineering and applied mechanics at the University of Virginia and his $\mathrm{PhD}$ degree in materials science and engineering at Northwestern University. He was awarded a National Research Council research fellowship for his postdoctoral work in the Polymers Division at the National Institute of Standards and Technology.

Crosby's research interests include surface and interfacial mechanics of polymers, the development and use of elastic instabilities for controlling interfacial properties, mechanical strength in polymer-nanoparticle composites, and the development of mechanical properties in biological sheets and soft materials.

As a faculty member at UMass Amherst, he has received several awards, including a National Science Foundation CAREER Award and the Army Research Office Young Investigator Award.

Crosby can be reached at the University of Massachusetts, Polymer Science and Engineering Department, 120

Governors Dr., Amherst, MA 01003, USA; e-mail crosby@mail.pse.umass. edu.

Kathryn A. Daltorio is an MS and PhD degree 


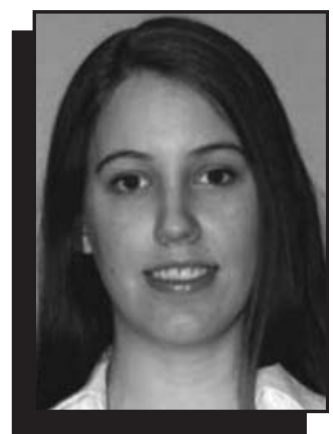

Kathryn A. Daltorio

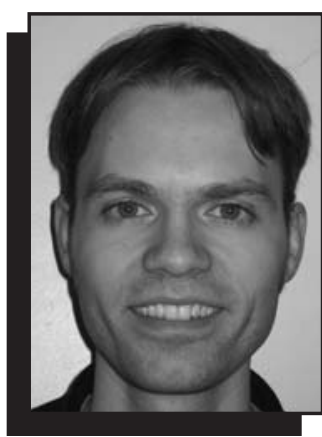

Nicholas J. Glassmaker

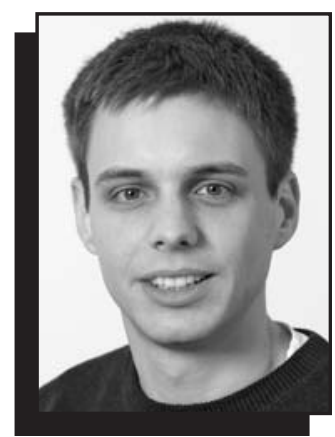

Christian Greiner

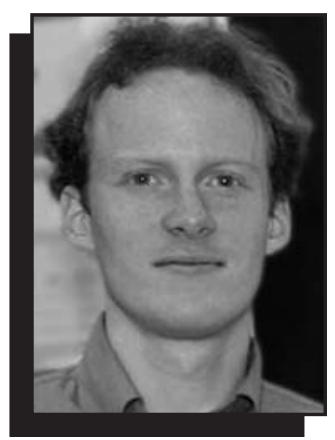

Andrew D. Horchler

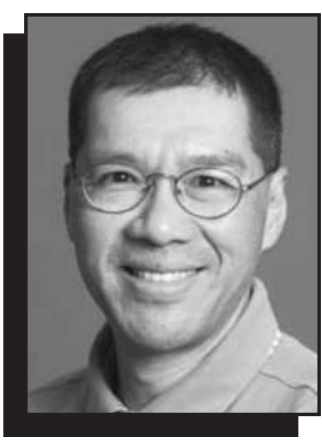

Chung-Yuen Hui
Science Foundation graduate research fellowship (2000-2003) and a Tau Beta Pi fellowship (2000).

Glassmaker can be reached by e-mail at nicholas.glassmaker@ espci.fr.

Nicholas J. Glassmaker is a postdoctoral researcher in the Laboratoire de PhysicoChimie des Polymères et Milieux Dispersés (PPMD) at the Ecole Supérieure de Physique et Chimie Industrielles (ESPCI) in Paris, France. He received his $\mathrm{PhD}$ degree in theoretical and applied mechanics from Cornell University in 2004. He then spent two years as a postdoctoral researcher in the

Department of Chemical Engineering at Lehigh University.

His research interests include mechanical problems of adhesion, fracture mechanics, nonlinear elasticity, and mechanical instabilities. While working toward his $\mathrm{PhD}$ degree,

Glassmaker focused primarily on theoretical and experimental aspects of the understanding and replication of gecko adhesion. Glassmaker's current research is focused on modeling the mechanical failure of pressure-sensitive adhesives. His awards include a National
Christian Greiner is a

$\mathrm{PhD}$ student in the department of Eduard Arzt at the Max Planck Institute for Metals Research in Stuttgart, Germany. He studied materials science in Stuttgart and wrote his diploma thesis at Northwestern University. At Northwestern, he worked in the group of David Dunand, studying superelastic NiTi foams. In 2004, Greiner graduated with honors and was awarded the Artur Fischer Prize of the University of Stuttgart for outstanding academic achievement. His current research interests focus on patterned elastomer surfaces for the study of size and shape effects in bio-inspired fibrillar adhesives.

Greiner can be reached at Max Planck Institute for Metals Research, Heisenbergstrasse 3, 70569 Stuttgart,

Germany; e-mail greiner@mf.mpg.de.

Andrew D. Horchler is an MS and PhD degree candidate in mechanical engineering and aerospace engineering at Case Western Reserve University in Cleveland, Ohio. Horchler received his BSE degree in mechanical engineering from Princeton

University in 2000.

As a member of the Biologically Inspired Robotics Laboratory at Case, he has designed and built six robotic vehicles and worked with others to develop robots that jump, fly, and climb walls. He collaborated with researchers at the University of Edinburgh to study issues of sensorimotor integration in insect behavior.

Currently, he is developing intelligent control algorithms for Case's 2007 DARPA Urban Challenge team.

Horchler's research interests include nonlinear systems, design and control of legged robots, and sensorimotor integration for mobile robots. His research has resulted in more than 20 publications, a patent (pending), several awards, and media recognition. He is a student member of the Society for Neuroscience and IEEE.

Horchler can be reached at the Department of Mechanical and Aerospace
Engineering, Case Western Reserve University, Glennan Building, Room 818, 10900 Euclid Ave., Cleveland, $\mathrm{OH} 44106-$ 7222, USA; e-mail adh9@po.cwru.edu.

Chung-Yuen Hui is a professor in the Department of Theoretical and Applied Mechanics at Cornell University. He joined Cornell after earning his PhD degree in applied mechanics from Harvard University in 1981. Hui received his undergraduate degree in physics and mathematics from the University of Wisconsin-Madison.

Hui can be reached by e-mail at ch45@ cornell.edu.

Anand Jagota is a professor of chemical engineering and director of bioengineering at Lehigh University. He earned his $\mathrm{PhD}$ degree in mechanical engineering from Cornell University in 1988 and his undergraduate degree in mechanical engineering from the Indian Institute of Technology, Delhi, in 1983.

Jagota worked at the DuPont Company from 1988 to 1994 and again from 1996 to 2004. From 1994 to 1996 , Jagota was an assistant professor of applied mechanics at the 


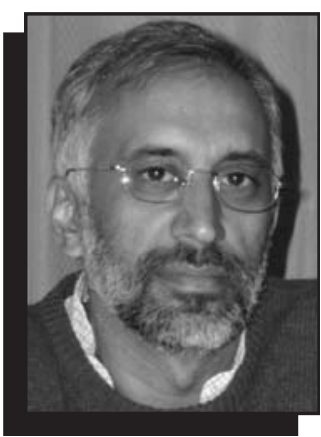

Anand Jagota

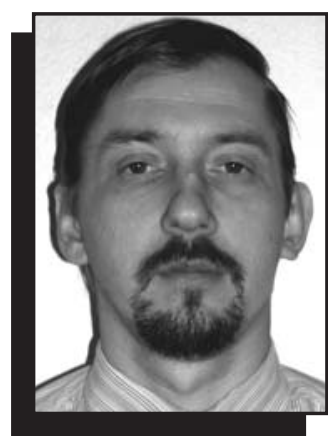

Andrei Peressadko

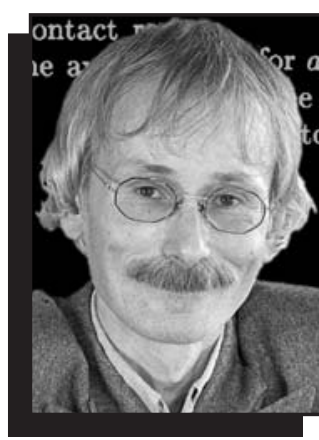

Bo N.J. Persson

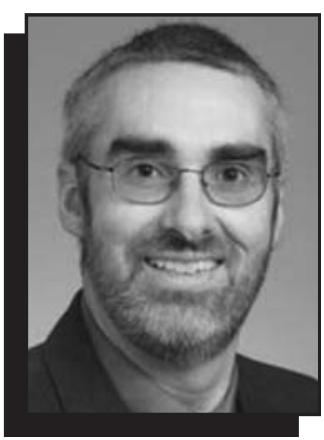

Roger D. Quinn

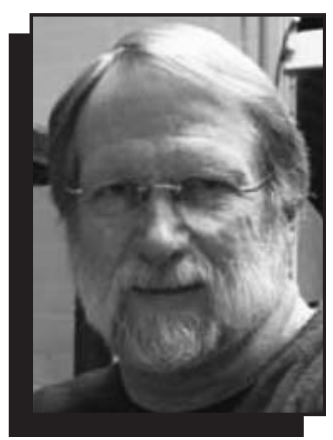

Roy E. Ritzmann
119361 Moscow, Russia; e-mail peressadko@ inbox.ru.

Bo N.J. Persson is a research scientist at Forschungszentrum Jülich, Germany, and is a consultant for the Pirelli Tire Company. Persson earned his $\mathrm{PhD}$ degree in theoretical physics at Chalmers Technical University in 1980. He worked at IBM Thomas J. Watson Research Center in Yorktown Heights, N.Y., from 1982 to 1983; at IBM Zürich Research Laboratory from 1987 to 1988; and has spent time at various universities and research centers. His main research interests include adhesion, friction, contact mechanics, and crack propagation-in particular, for rubber-like materials.

Persson can be reached at Forschungszentrum Jülich $\mathrm{GmbH}$, Institut für Festkörperforschung, D-52425 Jülich, Germany; tel. 49-246-161-5143, fax 49-246-161-2850, and e-mail b.persson@ fz-juelich.de.

Roger D. Quinn is the Arthur P. Armington Professor of Engineering at Case Western Reserve University in Cleveland, Ohio. Quinn received his PhD degree in engineering science mechanics from Virginia Tech in 1985 and his MS and BS degrees in mechanical engineering from the University of Akron in 1983 and 1980, respectively. He joined the Mechanical and Aerospace Engineering Department at Case in 1986.

Quinn has directed the Biorobotics Laboratory since its inception in 1990 and has been working with Roy Ritzmann since that time. His research, in collaboration with biologists including Ritzmann and Stanislav Gorb, is devoted to the development of robots and control strategies based upon biological principles. Quinn is the lead inventor of a group of robotic vehicles that benefit from abstracted biological principles. His current work includes developing robots that can climb vertical surfaces using animal-inspired materials and mechanisms and developing insectinspired intelligent systems to increase the autonomy of mobile robots.

Quinn has more than 200 publications and holds several patents. His collaborative work on behavior-based distributed control, autonomous robot climbing, and human-machine interfacing has earned awards from the IEEE.

Quinn can be reached at the Department of Mechanical and Aerospace Engineering, Case Western Reserve University, Glennan Building, Room 818, 10900 Euclid Ave., Cleveland, OH 441067222, USA; tel. 216-3683222 , fax 216-368-6445, and e-mail rdq@case. edu.

Roy E. Ritzmann is a professor of biology at Case Western Reserve University in Cleveland, Ohio. He received his undergraduate degree in zoology at the University of Iowa and his $\mathrm{PhD}$ degree in biology at the University of Virginia, working with DeForest Mellon Jr. Ritzmann was a postdoctoral researcher at Cornell University in the laboratory of Jeffrey M. Camhi, where he worked on the neural circuitry that underlies the escape system of the cockroach. Ritzmann has been a member of the faculty of the Biology Department at Case since 1977.

In recent years, the Ritzmann laboratory has exploited parallel analysis strategies in examining how insects deal with barriers to forward locomotion. Beyond the basic neurobiological principles of movement that this work has revealed, the understanding gained is being used by

collaborator Roger D.

Quinn in the design and implementation of legged robots. In return, many of the robots designed by Quinn's Biorobotics Laboratory provide hardware models in which biological hypotheses can be tested and refined.

Ritzmann can be reached at the Department of Biology, DeGrace Hall, Room 220, Case Western Reserve University, 10900 Euclid Ave., Cleveland, $\mathrm{OH}$ 44106-7080 USA; e-mail roy.ritzmann@case.edu.

Tian Tang is an assistant professor in the Mechanical Engineering Department at the University of Alberta, Canada. She received her BS degree in engineering mechanics from

Tsinghua University, Beijing, in 2001, and her $\mathrm{PhD}$ degree in theoretical and applied mechanics from Cornell University in 2005. At Cornell, Tang studied mechanics of adhesion in micro- to nano-sized systems under the supervision of Chung-Yuen Hui. Afterward, Tang worked with professor Anand Jagota in the Chemical Engineering Department 


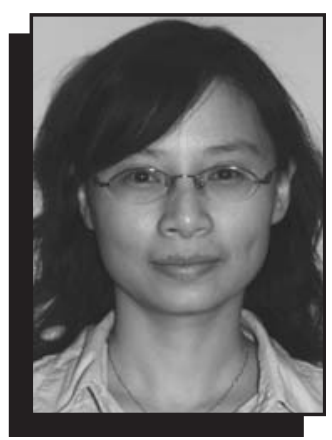

Tian Tang

at Lehigh University, where she investigated the mechanics and electrostatics of DNA-carbon nanotube hybrids.

Her general research interests are at the

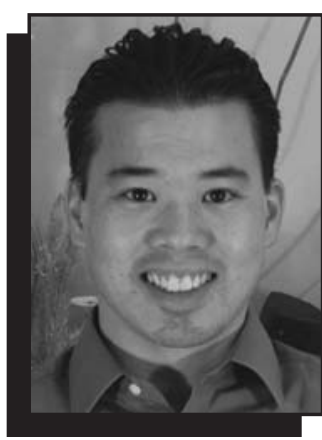

Terence E. Wei

interface of applied mechanics and materials science. Tang's recent studies include multiscale modeling and simulation of nanobiomolecular hybrid materials, adhesion in biological and

biomimetic systems, and statistical theory of failure mechanisms in compliant solids.

Tang can be reached at 4-9 Mechanical

Engineering Building, University of Alberta, Edmonton, AB T6G 2G8, Canada; tel. 780-492-5467 and e-mail tian.tang@ ualberta.ca.

Terence E. Wei received his $\mathrm{PhD}$ degree in mechanical engineering in 2005 from Case

Western Reserve

University in Cleveland, Ohio. While performing research at Case's
Biologically Inspired

Robotics Laboratory, he

developed many types of

vehicles, including

single-legged hopping

robots and six-legged

walking robots. He has

designed dynamic simu-

lations for the purposes

of optimizing robotic

design and robot-ground

interaction. Wei also

created several special-

ized apparatus for the

purposes of obtaining

insect locomotion and

climbing behavior data,

as well as novel feeding

mechanisms for robotic

manufacturing work

cells.

After finishing his $\mathrm{PhD}$ degree, Wei received an
Intelligence Community postdoctoral fellowship. As a postdoctoral fellow, he worked on the design and integration of insect-inspired attachment mechanisms for climbing robots. His other interests include mechanism design and vehicle dynamics.

Wei can be reached at the Department of Mechanical and Aerospace Engineering, Case Western Reserve University, Glennan Building, Room 818, 10900 Euclid Ave., Cleveland, $\mathrm{OH}$ 441067222, USA.
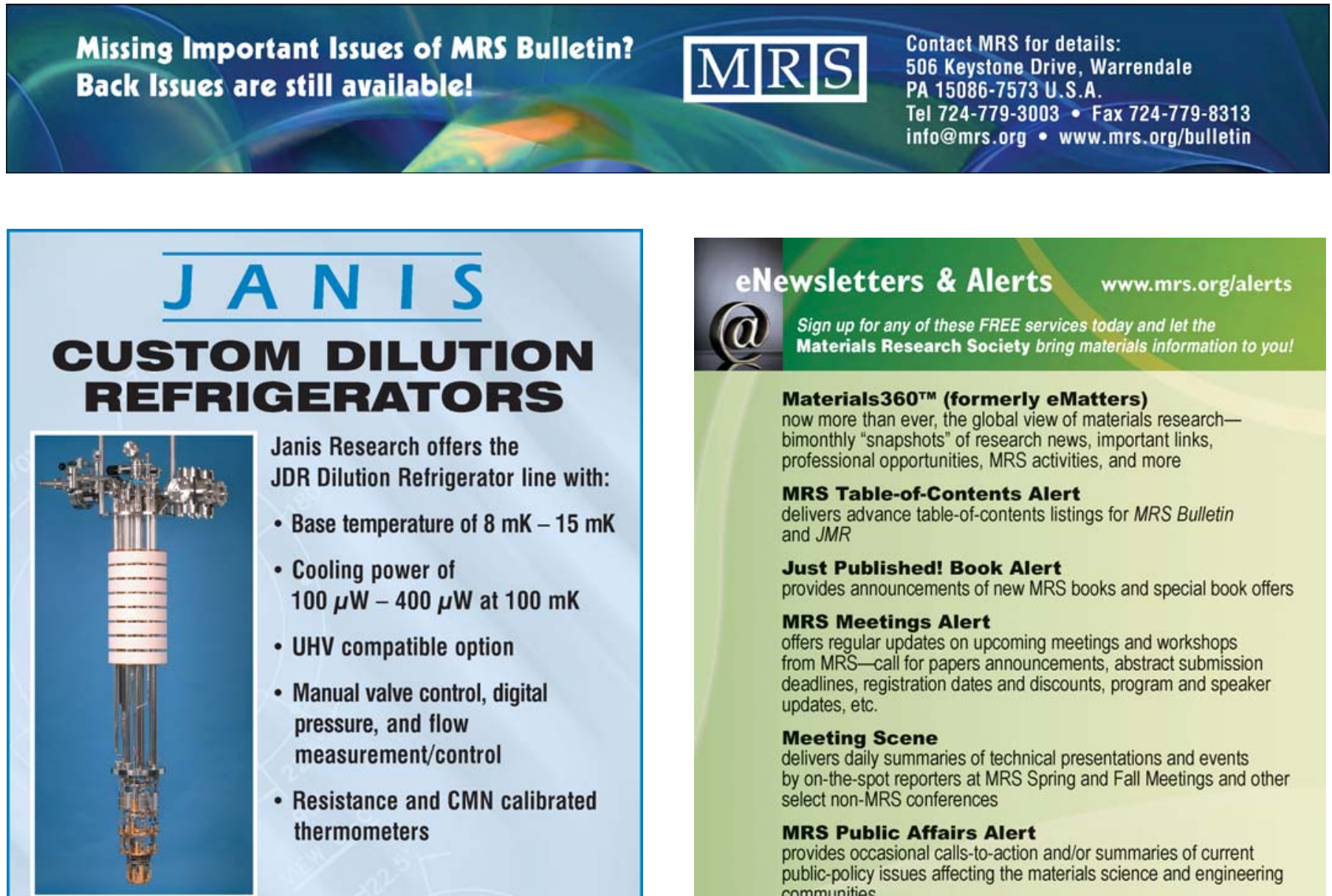

\section{A N I S}

MILUTION GERATORS

Janis Research offers the JDR Dilution Refrigerator line with:

- Base temperature of $8 \mathrm{mK}-15 \mathrm{mK}$

- Cooling power of $100 \mu \mathrm{W}-400 \mu \mathrm{W}$ at $100 \mathrm{mK}$

- UHV compatible option

- Manual valve control, digital pressure, and flow measurement/control

- Resistance and CMN calibrated thermometers
Janis Research Company

2 Jewel Drive Wilmington, MA 01887 USA

TEL +1978 657-8750 FAX +1978 658-0349 sales@janis.com Visit our website at WWW.janis.COm.

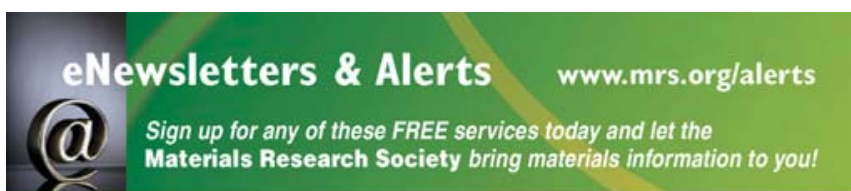

Materials $360^{\mathrm{rm}}$ (formerly eMatters)

now more than ever, the global view of materials researchbimonthly "snapshots" of research news, important links, professional opportunities, MRS activities, and more

MRS Table-of-Contents Alert

delivers advance table-of-contents listings for MRS Bulletin and JMR

Just Published! Book Alert

provides announcements of new MRS books and special book offers

MRS Meetings Alert

offers regular updates on upcoming meetings and workshops

from MRS - call for papers announcements, abstract submission deadlines, registration dates and discounts, program and speaker updates, etc.

\section{Meeting Scene}

delivers daily summaries of technical presentations and events by on-the-spot reporters at MRS Spring and Fall Meetings and other select non-MRS conferences

\section{MRS Public Affairs Alert}

provides occasional calls-to-action and/or summaries of current public-policy issues affecting the materials science and engineering communities

\section{Women in MS\&E}

an online forum for dialog among women working in, or pursuing education towards, a profession in materials science or engineering; women and men are both welcomed to participate 